\title{
KROPP, RUM OCH FRÄMLINGSSKAP I WILLEM FREDERIK HERMANS ROMAN NOOIT MEER SLAPEN (ALDRIG MERA SOVA, 1966)
}

\author{
Sophie Wennerscheid \\ Universiteit Gent \\ sophie.wennerscheid@ugent.be
}

\begin{abstract}
This contribution examines the representation of place and body in Willem F. Hermans novel Nooit meer slapen (1966) (Beyond Sleep). Special attention is paid to the question of how the protagonist, a young Dutch $\mathrm{PhD}$ candidate in geology, makes his way through Norwegian Finnmark, an area he does not know but is eager to explore. At the beginning of his journey, Alfred feels certain about the world's measurability and, consequently, the human capacity to control both the world and humanity's superior position in it. Soon, however, he learns about his body's embeddedness in nature and thus its fragility. Drawing on Maurice Merleau-Ponty's critique of the Cartesian worldview and the subject-object dichotomy, Hermans' novel is read as a critical engagement with unchallenged rationality and enlightenment.
\end{abstract}

\section{Nyckelord}

Kropp, rum, rörelse, identitet, kulturkonflikt, rationalitetskritik, destabilisering, osäkerhet.

Att resa med sitt kulturella bagage från ett land till ett annat är sällan okomplicerat. Det som man har med sig passar inte smidigt ihop med det man påträffar. Det gäller för flyktingar som för turister och vanliga resande. Men det gäller också för litterära verk och figurer som rör sig mellan olika länder. Romanen Nooit meer slapen (1966) av den nederländske författaren Willem Frederik Hermans är ett bra exempel på detta. Medan Hermans räknas som en av Nederländernas viktigaste författare omtalas han endast sällan i norra Europa. Nooit meer slapen betraktas som Hermans främsta roman. Att inte ens den har uppskattats i Norden är särskilt förvånansvärt eftersom den inte bara utspelas i den norska Finnmarken, utan också tar upp ett i nordisk litteratur ofta förekommande tema: spänningen mellan nord och syd, berg och dal, natur och kultur, det egna och det främmande.

Romanen handlar om den nederländske geologidoktoranden Alfred Issendorf som tillsammans med tre norrmän reser till Finnmarken för att forska om möjliga meteoritnedslag. Medan hans reskamrater känner till trakten mycket väl är han själv otränad, dåligt utrustat och utan norska språkkunskaper. Men han har mycket höga förväntningar och vetenskapliga ambitioner och tror sig kunna göra banbrytande nya upptäckter.

Ik zou het liefst een meteoriet vinden, een brok afkomstig uit de kosmos en ik zou willen dat het uit een material bestond, dat op aarde nog nooit was aangetroffen. De steen der wijzen, of minstens een mineraal dat naar mij zou worden genoemd: Issendorfiet (Hermans 49).

Tijdschrift voor Skandinavistiek 36(2), 2018/19 (cc) Er

\footnotetext{
Except where otherwise indicated, the content of this article is licensed and distributed under the terms of the Creative Commons Attribution 3.0 License, which permits unrestricted use, distribution, and reproduction in any medium, provided the original work is properly cited.
} 
Helst skulle jag vilja hitta en meteorit, en bumling härstammande ur kosmos, och den borde bestå av ett material som man inte tidigare har hittat här på jorden. De vises sten, eller åtminstone ett mineral som blir uppkallat efter mig: Issendorfiet. ${ }^{l}$

Men försöket att lämna den bekanta terrängen bakom sig och bege sig ut i det okända fjällandskapet misslyckas. Alfred plågas av den ovana tunga ryggsäcken och de otaliga mygg som vill honom illa. Men framför allt lider han under den brännande midnattssolen som hindrar honom att sova. Snart börjar han också betrakta sina tre norska medresenärer som konkurrenter som vill sabotera hans forskning. Att de fyra unga männen bara har en bristfällig engelska som gemensamt språk bidrar inte heller till en förbättring av kommunikationen. Ju noggrannare Alfred försöker förstå det som pågår runt omkring honom, desto mer tappar han greppet om allt. Steg för steg förlorar han orienteringen i verkligheten och går vilse i sig själv. Subjektets positionering $\mathrm{i}$ rummet decentreras, fasta konturer löses upp och det rumstidsliga koordinatsystemet kröks.

Med avstamp i fenomenologisk rums- och kroppsteori vill jag i det följande undersöka huruvida kroppens rörelse genom det okända rummet ifrågasätter såväl kroppens koherens som rummets kontinuitet. Närmare bestämt kommer jag att granska hur Hermans framställer protagonistens rörelser upp och ner i det norska fjällandskapet som identitetsdestabiliserande rörelser. En annan aspekt som jag vill undersöka är hur Alfred uppfattar sin kropp som främmande och hur han på grund av denna främlingskänsla får insikt i livets obeständighet. Genom att fokusera på sammanhanget mellan kropp, rum och främlingskap vill jag bidra till en bättre förståelse av Hermans poetik som är präglad av såväl formella som innehållsmässiga brytningar, diskontinuiteter, avbrott och störtningar. Eftersom Hermans är så pass okänd i Skandinavien vill jag emellertid först redogöra för hans liv och mottagande i Norden.

Willem Frederik Hermans föddes 1921 i Amsterdam och dog 1995 i Utrecht. Tillsammans med Harry Mulisch och Gerard Reve räknas han till De Tre Stora (De Grote Drie) inom den holländska efterkrigslitteraturen. Willem Hermans var utbildad geolog. Han var doktor i geografi och från och med 1958 fram till 1973 anställd vid universitet i Groningen. 1962 introducerades Hermans för en svensk publik med sin roman Mörkrummet (De donkere kamer van Damokles, 1958). Boken utspelas under andra världskriget och skildrar ockupationens Holland. 1965 kom novellsamlingen Paranoia (1953) ut på svenska och tre år senare översattes Nooit meer slapen till svenska och publicerades under titeln Aldrig mera sova (1968). Upplagan var 3300 exemplar och såldes snart slut (Van der Valk, 1996, 8). Alla tre böcker översattes av Brita Dahlman och publicerades hos Norstedts (Schulz 1981). I Norge introducerades Willem Herman i samma år och med samma bok som i Sverige, dvs. med översättningen av De donkere kamer. Nooit meer slapen däremot publicerades först 30 år senare, alltså 1992. Upplagan var med bara 2200 exemplar relativt liten, men enligt den nederländske litteraturvetaren Arno van der Valk fick boken ändå en del uppmärksamhet och sålde bra.

\footnotetext{
${ }^{1}$ Eftersom jag inte fick tag i Brita Dahlmans översättning av boken är alla översättningar ur romanen gjorda av mig.
}

Tijdschrift voor Skandinavistiek 36(2), 2018/19 (cc) Er 
I en intervju med Hermans som 1992 publicerades i den norska tidningen Aftonbladet, och som van der Valk tre år senare översatte till nederländska, framhävs de norska skribenternas särskilda intresse för de mytbildande aspekterna i Hermans roman: midnattssolen, gravlaxen och myggen. Hermans poängterar emellertid:

Jeg er klar over at boken har virket myteskapande. Men for meg er fiksjon bare interessant dersom den også viser ærbodighet for virkeligheten. Intet av den ytre rammen i Aldri sove mer er opdiktet. Det er fullt ut mulig å følge hovedpersonens fotspor over Finnmarksvidda.

Att yttrandet måste tas med försiktighet kommer vi snart att se. Men först några ord om fenomenologisk kropps- och rumsteori.

Fenomenologin utgår ifrån att människan aldrig får veta något om 'tinget i sig'. Det är bara vår förnimmelse av tingets gestalt, sättet som det syns för oss, som vi kan uppfatta. I sitt huvudverk Phénémonologie de Perception (Varseblivningens fenomenologi, 1945) betonar den franske filosofen Maurice Merleau-Ponty dessutom att tingets uppfattning inte sker kognitivt utan via vår kropp (Merleau-Ponty, 2000). Eftersom världen förmedlas genom kroppen är världen inte avskild från själva kroppen. Den cartesiska motsättningen mellan subjekt och objekt upphävs. Och med det också föreställningen av att subjektet kan härska fritt och suveränt över objektet. Detta gäller inte minst för kroppens relation till det konkreta rummet kroppen rör sig i. Rummet blir till i kontakt med kroppen så som kroppen blir till i den rumsliga praktiken. Detta har stora konsekvenser för individens självuppfattning. Den blir till beroende på hur rummet uppfattas.

I sin artikel "Fort-Schritte, Gedanken-Gänge, Ab-Stürze" fortsätter den tyska litteraturvetaren Doris Bachmann-Medick det fenomenologiska resonerandet. Hon påvisar inte bara rörelsens betydning för individens själv- och världsbild utan gör också uppmärksam på att växelverkan mellan kroppslig rörelse och rumskonstituering följer specifika kulturella mönster. På 1800talet förknippades rörelse till exempel ofta med framgång. Den betraktades som expansiv, linjär, målinriktad och kontrollerad. I synnerhet gåendet ansågs som en självkontrollerad rörelseteknik (Bachmann-Medick, 2009, 263). Men motsvarande denna tendens fanns det redan då litterära texter där brytningar och störningar spelade en viktig roll. Bachmann-Medick sammanfattar:

Als eine Raumwahrnehmungskunst ist die Dichtung schon im 18. Jahrhundert an Verwerfungen, Brüchen und Störungen interessiert. So wird in literarischen Texten die (horizontal) gerichtete Bewegung der Expansion immer wieder von Gegenbewegungen unterlaufen. In der Literatur der Romantik etwa nutzte die zielgerichtete Bewegung des Wanderns besonders das Gebirge und die Schluchten [...], um solche Gegenbewegungen, ja überhaupt ganz andere Raumvorstellungen freizusetzen.

Bachmann-Medick talar i detta sammanhang om en "Umbruch in der Subjektverortung" (Bachmann-Medick, 2009, 263). Det vill säga subjektet förlorar självkontrollen och börjar

Tijdschrift voor Skandinavistiek 36(2), 2018/19

\footnotetext{
Except where otherwise indicated, the content of this article is licensed and distributed under the terms of the Creative Commons Attribution 3.0 License, which permits unrestricted use, distribution, and reproduction in any medium, provided the original work is properly cited.
} 
stappla och svaja. Det går runt i cirklar eller till och med tappar balansen och faller baklänges. Hur det ser ut i Nooit meer slapen ska nu visas.

Bokens protagonist och jag-berättare, den unge Alfred, kännetecknas av sitt stora behov av att ha kontroll över sitt liv. Redan när Alfred börjar sin resa och anländer till Oslo för att träffa en viss professor Nummedal som enligt Alfreds nederländska promotor Sibbelee ska ge honom de flygfoton han behöver för att kunna hitta meteoritkratrar blir det tydligt. Alfred räknar med att allt kommer att ske som avtalat. Han har stämt ett möte med Nummedal klockan halv elva. Han kontrollerar sin klocka, allt verkar vara korrekt. "Onwillekeurig kijk ik op mijn polshorloge dat ik gisteren bij aankomst in Oslo gelijk gezet heb op Noorse zomertijd. Half elf." (7) [Ofrivilligt tittar jag på mitt armbandsur som jag satt på norsk sommartid när jag anlände till Oslo igår. Halv elva.] Men Alfreds antagande att kunna räkna på klocktiden visas vara lika felaktigt som hans förtroende för att alla andra mätinstrument som han har skaffat - kompasser, teodoliter, mätband, kartor osv. - skulle kunna hjälpa till att orientera honom i rum och tid. I handlingens början är Alfreds förtroende för sådana instrument emellertid fullkomligt orubbat. Att vara vetenskapsman betyder för honom att kunna mäta och beräkna världen. "Onderzoeken is meten" (39) [Att undersöka är att mäta] låter hans livs motto. Han förklarar:

Bij mij mag nooit iets misgaan. Dingen laten slingeren, onvoorbereid in situaties terechtkomen, met je mond vol tanden staan, grotere gruwel ken ik niet. Ik zal niet per ongeluk doodvallen in een bergspleet, zoals mijn vader en als het zou gebeuren, dan zal ik er op voorbereid moeten zijn. Uitglijden zal mij niet verrassen. Ik zal mij weten vast te grijpen of mijn val zien te breken. (Hermans, 2014, 43)

Ingenting får misslyckas. Att inte ha koll på allt, att oförberett råka ut för vissa situationer, att inte veta vad som ska göras, jag kan inte tänka mig något mer förfärligt. Jag kommer aldrig att av misstag störta ner i en skreva, så som det hände med min far, och om det ändå skulle hända så är jag helt säkert förberedd på det. Jag kommer inte att bli överrumplad om jag förlorar fästet. Jag vet hur jag kan hålla fast mig eller hur jag skulle kunna stoppa mitt fall.

Men just denna förvissning om att allt kan förutses och planeras visar sig vara fel. På sin expedition behöver Alfred övervinna otaliga skarvar och klyftor och floder, men istället för att bemästra dem med skicklighet hotas han hela tiden med att förlora fotfästet. Världen visar sig vara slipprig, ostabil, vacklande och opålitlig. Varje steg innebär en risk.

De voeten moeten precies boven op een steen geplaatst worden om er niet af te glijden. Elke stap vereist berekening, geen enkele beweging kan gemaakt worden zonder de gedachte: Straks schiet je been tussen twee, drie stenen in, raakt klem, je valt. Het been knapt doormidden als een bezemsteel. (255)

Fötterna måste sättas precis på stenens topp, annars halkar man omkull. Varje steg måste beräknas, det finns inte en enda rörelse man kan göra utan att

Tijdschrift voor Skandinavistiek 36(2), 2018/19

\footnotetext{
Except where otherwise indicated, the content of this article is licensed and distributed under the terms of the Creative Commons Attribution 3.0 License, which permits unrestricted use, distribution, and reproduction in any medium, provided the original work is properly cited.
} 
tänka: Meddetsamma skjuter ditt ben ner mellan två, tre stenar, kläms in, du störtar. Benet bryts som en sopkvast.

Alla stenar och bumlingar är naturligt förekommande element i Finnmarken. I Hermans textuella rum får de emellertid en symboliskt laddad betydelse. Hällmarken gör det omöjligt att röra sig rakt fram och hitta sin väg genom rum och tid. Alfreds expedition såsom Hermans litterära värld framstår därför som "absurd, undanglidande, motsägelsefull (Schultz, 1981, 16). Å ena sidan följer berättelsens gång expeditionens förlopp i tid och rum, men å andra sidan berättas det om tids- och rumskoordinaterna på ett sådant sätt att det ändå inte är möjligt att noggrant följa Alfreds spår genom vildmarken. Detta på grund av att Alfred själv inte riktig vet vart han går. Den tunga ryggsäcken gör att han inte kan höja blicken och myggnätet inskränker hans syn ytterligare. Nästan som en blind följer han sina norska kollegor. Förutom den böjda kroppshållningen är det Alfreds utdragna tidsupplevelse som ytterligare bidrar till att han förlorar kontroll över tid och rum.

Ik kijk op mijn horloge. [...] Het is vijf voor negen. Om kwart voor negen hebben we Qvigstad en de sterke man teruggevonden. Dus al tien minuten op weg. Iedere stap voelt aan als de laatste die ik kan doen. Mijn horloge heeft een centrale secondenwijzer. Zodoende kan ik precies zien hoe lang elke stap duurt: twee seconden. Hoe groot is elke stap? Niet meer dan zestig centimeter denk ik. Dat maakt dus dertig maal zestig centimeter per minuut. Is achttien meter. Is zestig maal achttien, is... is... nul, zes maal acht is achtenveertig, zes plus vier is tien, is een, nul acht, nul. Is... ruim een kilometer in een uur? (125)

Jag tittar på min klocka. [...] Det är fem i nio. Kvart i nio har vi träffat Qvigstad och den starka mannen igen. Då har vi alltså varit vägen i tio minuter. Varje steg känns som om det vore det sista jag kan ta. Min klocka har en central sekundvisare. Därför kan jag exakt se hur lång tid det tar för ett steg: två sekunder. Hur stort är varje steg? Inte mer än sextio centimeter antar jag. Det betyder då trettio gånger sextio centimeter per minut. Det gör arton meter. Sextio gånger arton är ... är noll, sex gånger åtta är fyrtioåtta, sex plus fyra är tio, är ett, noll åtta, noll. Är ... runt en kilometer per timme?

Alfred upplever en tydlig diskrepans mellan uppmätt tid och upplevd tid. Rummets tidsdimension har blivit opålitlig. Alfred, och med honom läsaren, kan inte längre orientera sig i rumstiden. Men även om Alfred här får en aning om att det inte fungerar att nå sitt mål genom beräkningar håller han ändå fast vid den föreställningen. Han fortsätter räkna tid och kilometer, tittar om och om igen på sin karta, försöker orientera sig och pigga upp sig själv. "Sjok verder, zet de ene voet voor de andere. Iedere voetstap is er een. Is het geen mirakel? Een stap. Een enkele stap en de afstand tot de top is alweer korter. [...] Stap. Tussen de stenen, mos. Daartussen plekjes met niets. [...] Mijn horloge staat op vijf over half tien." (130) [Kom nu, sätt den ena foten framför den andra. Varje steg är ett steg. Är det inte ett under? Ett steg. Ett enda steg och avstånden till toppen har blivit mindre. [...] Steg. Mellan stenarna, mossa. Och där

Tijdschrift voor Skandinavistiek 36(2), 2018/19 (co) EY

Except where otherwise indicated, the content of this article is licensed and distributed under the terms of the Creative Commons Attribution 3.0 License, which permits unrestricted use, distribution, and reproduction in any medium, provided the original work is properly cited. 
emellan små bitar av ingenting. [...] Min klocka visar fem över halv tio.] Allt blir lagt under berättarens lupp. Men precis på grund av detta dras tiden ut så mycket på längden att det linjära loppet liksom punkteras. Tiden imploderar och förlorar sin riktning.

Men det är inte bara det fysiska gåendet som inte längre kan bemästras. Likadant blir det omöjligt att kontrollera de psykiska rörelserna, dvs. tankegångarna. Oväntat dyker tvångstankar, våldsfantasier och vanföreställningar upp. I Alfreds fall är det framför allt tanken att misslyckas med expeditionen eller att bli bedragen av de andra som plötsligen gör sig gällande. Det som Bachmann-Medick framhäver, nämligen att sammanhanget mellan gåendet, tankegången och subjektets positionering bryts upp i vissa texter (265), gäller alltså också för Hermans roman. Okontrollerbara fantasier korrumperar den målmedvetna tankebanan och samtidigt också den konkreta vandringen genom fjället.

Gång på gång blir Alfred varse om att han är främmande i vildmarken, att han inte hör dit. Därmed uppfylls på sätt och vis den norske professor Nummedals chauvinistiska yttranden om Alfreds status som nederländare i Norge. Nummedal menar nämligen att en nederländare per definition inte tillhör det hårda, karga och höga livet. Enligt honom är Nederländerna ett land som "eigenlijk aan de vissen toebehoort" (19) [egentligen tillhör fiskarna]. Norge däremot är för honom ett land där man har "vaste rotsen onder je voeten" (18) [fast mark under foten]. Att som nederländare bege sig på en vetenskaplig expedition till Norge är därför en absurd föreställning för Nummedal. Men Nummedals åsikt att Norge är ett land där man har fast mark under fötterna visas vara en fatal missbedömning. Det blir tydligt när det i romanens slut faktiskt är norrmannen Arne som halkar på en klippa och dör - och inte den hela tiden stapplande Alfred.

Alfred har emellertid lärt sig något, nämligen att världen inte kan kontrolleras. Så som Merleau-Pontys fenomenologi kan uppfattas som en kritik mot en världsbild som utgår från den mänskliga andens oberoende och frihet från den materiella världen kan därför också Hermans roman läsas som en uppgörelse med det objektiva och naturvetenskapliga tänkandet. Rationalitet och mätinstrument är inte till stor nytta när det gäller att hitta sin väg genom det vilda och oländiga livet. Snarare är det insikten att livet är något mycket fragilt och något som egentligen inte kan skyddas som bidrar till att Alfred får tillgång till livets hemligheter. Först efter att han har insett att han inte längre har något och inte längre vet något alls, efter han har förlorat kompas, karta och klocka, slutar han jämra sig och upplever livets rikedom. Han går ut och simmar, tvättar sig med ett stycke såpa som han har hittat i sin ryggsäck, och känner sig fri och lycklig.

Dan buig ik mij, bedek mijn hele huid met schuim, loop het water in tot kniehoogte, laat mij naar voren vallen en zwem. [...] Overal door liefderijk water omhuld te zijn, nergens pijn of weerstand meer ontmoeten, is nog heerlijker dan slapen. (262)

Och så böjer jag mig ner, täcker hela min kropp med skum, springer ut $i$ vattnet till knäna och låter mig falla framåt och simmar [...]. Att vara omsluten av underbart vatten, att ingenstans känna smärta, att inte möta något motstånd, det är härligare än att kunna sova.

Tijdschrift voor Skandinavistiek 36(2), 2018/19

Except where otherwise indicated, the content of this article is licensed and distributed under the terms of the Creative Commons Attribution 3.0 License, which permits unrestricted use, distribution, and reproduction in any medium, provided the original work is properly cited. 
Inte bara nord och syd, berg och dal, utan också kultur och natur verkar ha försonats här. Kroppen är inte längre främmande för sig själv utan har så att säga kommit hem - även om det här kanske handlar om en regressiv hemkomstfantasi, en fantasi om att vara tillbaka i livmodern där det är tryggt och tyngdlöst.

\section{Bibliografi}

Aaslested, Peter (1992). Ekstreme Finnmark, Aftenposten, 1 april. http://www.dbnl.org/tekst/_par009199601_01/_par009199601_01_0049.php

Bachmann-Medick, Doris (2009). Fort-Schritte, Gedanken-Gänge, Ab-Stürze: Bewegungshorizonte und Subjektverortung in literarischen Beispielen. In Wolfgang Hallet \& Birgit Neumann (red.), Raum und Bewegung in der Literatur. Die Literaturwissenschaften und der Spatial Turn (pp. 257-279. Bielefeld: transcript.

Hermans, Willem Frederik (1966/2014). Nooit meer slapen. Amsterdam: De bezige bij.

Merleau-Ponty, Maurice (2000). Fenomenologins kropp. Göteborg: Daidalos.

Schultz, Peter (1981). Nederländsk litteratur. En annoterad förteckning över holländsk och flamländsk skönlitteratur efter 1945 i svensk översättning.

Van der Valk, Arno (1996). Alfred Issendorfs terugkeer naar het Norden. Noorse belangstelling voor Nooit meer slapen. De parelduiker, 5. http://www.dbnl.org/tekst/ _par009199601_01/_par009199601_01_0049.php 